\title{
Física computacional aplicada no ensino de física nuclear
}

\author{
Felipe, P. S., Paschoa, A.,Junior, V., Passamai, J. L. Junior, Pinheiro, C.J.G. \\ Departamento de Química e Física, Campus Alegre - Universidade Federal do Espírito Santo, ES, Brasil
}

\begin{abstract}
Resumo
Há muitas décadas países desenvolvidos e emergentes buscam soluções para o problema da falta de energia. A energia nuclear, por ser uma forma de energia limpa, tem sido uma dessas soluções, porém, ainda produz muito pavor ao ter seu nome pronunciado. Com intuito de minimizar esse pavor, aumentar 0 conhecimento e o número de profissionais na área nuclear diversas universidades optaram pela disciplina Física das Radiações como parte do currículo dos cursos de Física. Em alguns cursos a disciplina é obrigatória (Física Médica), optativa nos cursos de Bacharelado e Licenciatura em Física e eletiva em outros cursos (Biologia, Engenharia Química e Engenharia de Alimentos). Os temas radioatividade e energia nuclear também têm sido estendidos ao ensino médio. A Física das Radiações se interessa na transferência de energia da radiação para matéria após as interações. A Física das Radiações é a base para um curso de Física Nuclear. Neste trabalho visamos estudar a desintegração nuclear utilizando programação em Python com intuito de compreender melhor o conceito de radioatividade. Os resultados mostram o potencial da Física Computacional no Ensino de Física das Radiações.
\end{abstract}

Keywords (Palavras chaves): Radiação ionizante, Python, Radioatividade.

\section{Introdução}

Nos últimos anos a Física Nuclear utilizando os conceitos de Física das Radiações tem contribuído de forma marcante no avanço científico e tecnológico através dos estudos das radiações e suas interações. A Física das Radiações se interessa na transferência de energia da radiação para a matéria após as interações [1]. Tem aplicações na medicina, no tratamento de tumores e irradiação de sangue, no planejamento energético para obtenção de energia nuclear, na Ciência e Tecnologia de Alimentos irradiando diversos tipos de alimentos com o intuito de promover maior tempo de prateleira, na gemologia agregando valores a pedras preciosas e tantas outras áreas [2]. Apesar de suas inúmeras aplicações e benefícios a energia nuclear também pode oferecer riscos sérios a humanidade [3].

O pontapé inicial se dá em 1896 quando Antonie Henri Becquerel inicia a Física Nuclear com seus estudos sobre materiais fosforescentes até chegar a sais de urânio. A seguir Becquerel apresenta suas descobertas a Pierre Curie e a Mme. Curie. Em, 1903 o casal em parceria com Becquerel receberam o prêmio Nobel de Física. Foram os Curie que cunharam pela primeira vez o termo radioatividade.

Anos depois a ciência revela que a emissão espontânea de partícula ou energia proveniente do interior de um núcleo atômico nada mais é do que uma desintegração nuclear ou decaimento radioativo [4].
Em 1902 Ernest Rutherford e Frederick Soddy publicaram um artigo aonde eles estudaram quantitativamente a razão de decaimento [4]. A Lei da Desintegração Nuclear permite saber e é melhor compreendida se considerarmos uma amostra de um nuclídeo radioativo, onde NO é o número de núcleos presentes na amostra no instante $\mathrm{t}=0, \mathrm{~N}(\mathrm{t})$ é o número de núcleos que ainda não decaíram e $\lambda$ é a constante de desintegração. Esta constante é a probabilidade de decaimento por unidade de tempo [5-7].

$$
N(t)=N_{0} e^{-\lambda t}
$$

A constante de desintegração nuclear $(\lambda)$ pode determinar o tempo durante o qual a amostra do material radioativo é reduzida à metade do seu valor inicial (meia-vida $\mathrm{t}_{1 / 2}$ ) $t_{1 / 2}=\frac{\ln (2)}{\lambda}(2)$ e a meia vida $(\mathrm{T})$ que é a média ponderada dos tempos de vida de cada núcleo da amostra $T=\frac{1}{\lambda}(3)[6]$.

Experimentos envolvendo Física das Radiações são caros e, no geral, necessitam aprovação da Comissão Nacional de Energia Nuclear (CNEN). Ciente da importância do estudo desta disciplina é justa a utilização da Computação como auxiliadora para modelar diversas situações. 
Desta forma o objetivo deste trabalho é desenvolver alternativas para o ensino de Física das Radiações usando conhecimentos de programação Python.

\section{Metodologia}

Neste trabalho estudamos uma amostra de $\operatorname{Rb}^{82}(\lambda=$ $9,24 \times 10^{-3} \mathrm{~s}^{-1}$ ) conforme proposto por Paulo Murilo Oliveira e Suzana Maria Oliveira [7]. Neste trabalho abordaremos apenas dois dos cinco algoritmos propostos em [7].

Primeiro, construímos um gráfico com o número de núcleos ainda radioativos em função do tempo. Para a construção deste gráfico foi considerado $N(0)=1000$ núcleos radioativos iniciais e para simplificar o gráfico foram assinalados valores obtidos a cada 10 segundos.

Num segundo momento o algoritmo reconstrói o gráfico citado acima adotando escala logarítmica no eixo vertical, ou seja, o logaritmo Neperiano $\operatorname{lnN}(\mathrm{t})$ de cada um dos valores de $\mathrm{N}(\mathrm{t})$ calculados anteriormente.

\section{Discussão}

No figura 1 é possível verificar que a radioatividade do Rb82 foi reduzida à metade depois de decorridos $75 \mathrm{~s}$ (ou 1minuto e 15 segundos). Tal fato foi comprovado com o primeiro algoritmo de [7]. Com construção a do Figura 2 foi possível calcular o coeficiente angular da reta. Permitindo, assim, comparar com a constante de desintegração nuclear do $\mathrm{Rb}^{82}$ e mostrar que a equação (1) é a forma analítica que descreve o decaimento.

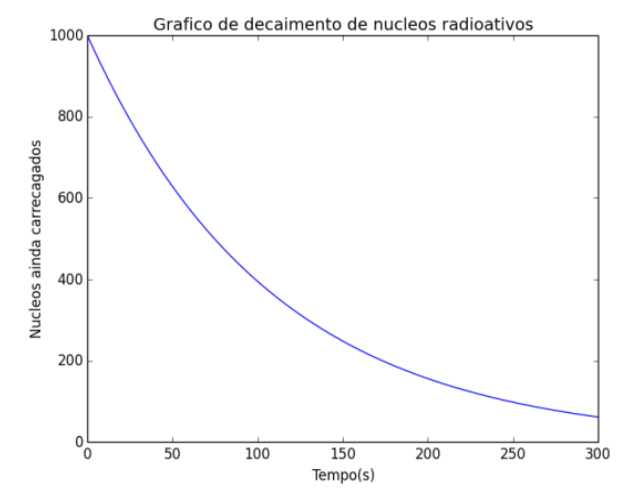

Figura 1: Decaimento dos núcleos radioativos

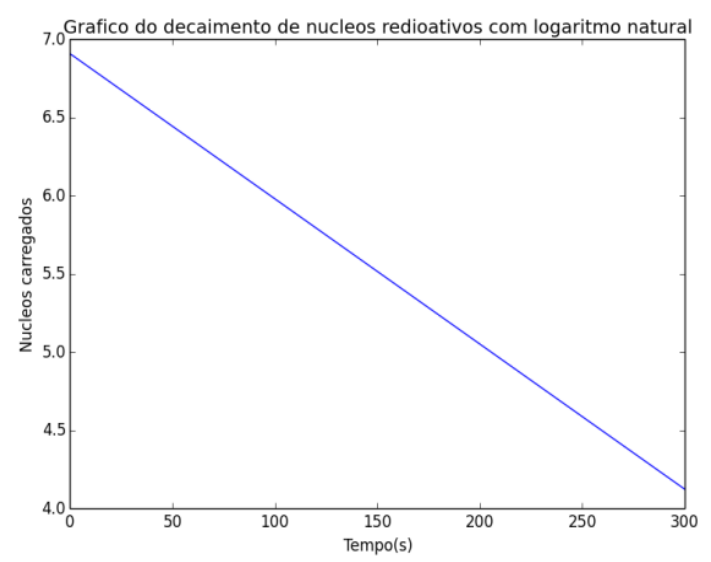

Figura 2: Decaimento dos núcleos radioativos com logaritmo natural

\section{Referências}

[1] YOSHIMURA, E. M. Revista Brasileira de Física Médica, 3(1): 57-67, 2009.

[2] DANIEL, H. U. Estudo Sobre o Gás Ozônio Formado no Processo de Irradiação Industrial com Cobalto-60 e seu Impacto no Meio Ambiente. Dissertação (Mestre em Ciências em Tecnologia Nuclear) IPEN, USP, 2013.

[3] MILANEZ, J. V.; ALMEIDA, R. D.; DO CARMO, F. S. Revista Ciências do Ambiente, On-Line, vol. 2, número 1, 2006.

[4] OKUNO, E.; YOSHIMURA, E. M., Física das Radiações. São Paulo: Oficina de Textos: 2010.

[5] CHUNG, K. C., Introdução à Física Nuclear - Rio de Janeiro: Editora UERJ, 2001

[6] TAUHATA, L.; SALATI, I. P. A.; DI PRINZIO, R.; DI PRINZIO, A. Radioproteção e Dosimetria: Fundamentos. $5^{a}$ revisão. Rio de Janeiro, IRD/CDTN, 2003.

[7] de OLIVEIRA, P. M.; de OLIVEIRA, S. M. M., Física em Computadores - São Paulo: Editora Livraria da Física, 2010. 